\title{
Wellbeing and Society: Towards Quantification of the Co-benefits of Wellbeing
}

\author{
Anna Maccagnan ${ }^{1}$ (D) $\cdot$ Sam Wren-Lewis ${ }^{2} \cdot$ Helen Brown ${ }^{2} \cdot$ Tim Taylor $^{1}$
}

Accepted: 12 December 2017 / Published online: 5 January 2018

(C) The Author(s) 2018. This article is an open access publication

\begin{abstract}
The objectives of this paper are twofold. First, it reviews the empirical evidence showing the existence of linkage between wellbeing and possible co-benefits, investigating in particular the positive effect that happiness and life satisfaction can have on health, social outcomes, employment, education and environmental behaviours. Second, it presents the valuation methods that have been proposed in the literature to place a monetary value on these outcomes. With wellbeing having become more and more relevant for individuals and policy makers, the full understanding of the co-benefits of wellbeing is central for the design and development of wellbeing interventions. As a consequence, the evaluation of the co-benefits of wellbeing is of crucial importance for the appropriate allocation of resources towards such strategies.
\end{abstract}

Keywords Life satisfaction · Co-benefits of wellbeing $\cdot$ Non-market outcomes ·

Valuation

\section{Introduction}

There is an increasing awareness of the importance of happiness and satisfaction with life, both among individuals and policy makers. The Stiglitz-Sen-Fitoussi Commission (2009) has for example pointed out that the way the individual perceives how well his or her life is going should be considered alongside other observable objective indicators of economic and social wellbeing. Moreover, subjective wellbeing is not only "intrinsically" but also "instrumentally" important for the individuals (Alkire 2015; De Neve et al. 2013): enhanced subjective wellbeing has been shown to lead to a number of better life outcomes,

Anna Maccagnan

a.maccagnan@exeter.ac.uk

1 European Centre for Environment and Human Health, University of Exeter Medical School, Knowledge Spa, Royal Cornwall Hospital, Truro TR1 3HD, UK

2 Happy City, Canningford House, 38 Victoria Street, Avon, Bristol BS1 6BY, UK 
such as better health status, more satisfactory social relationships, higher productivity and increased educational achievements.

A comprehensive evaluation of subjective wellbeing should therefore take into account not only its intrinsic value (i.e. the direct benefit derived from it), but also the effect of subjective wellbeing on other dimensions of life. In this paper, we are particularly interested in the secondary benefits - or co-benefits - of subjective wellbeing. These are defined as the outcomes that are not the main objective of a policy intervention, where the main or primary outcome targeted is taken to be that of subjective wellbeing. Benefits in terms of improved health, education and social relationships may for example occur, but these are secondary or "co-benefits".

While there has been increasing attention paid to the valuation of the intrinsic value of subjective wellbeing (e.g. Cox et al. 2012), it is probably the assessment of the co-benefits of subjective wellbeing improvements which is of more interest from the point of view of policy-makers. These co-benefits are often measurable and can be considered more tangible by policy-makers than subjective wellbeing in and of itself, and so it is important that they are properly assessed. This is very relevant for policy-makers working in these fields, as it enables the design of new-and possibly innovative-policies and the comparison of costs and benefits of different interventions. The evaluation of co-benefits of subjective wellbeing is in fact likely to yield potentially significant gains over and above the direct benefits to individuals.

The goals of the paper are twofold. First, it presents a review of the empirical evidence analysing the link between subjective wellbeing and the following life outcomes: health, social outcomes, employment, education and environmental behaviours. Our main objective is to synthesise the evidence on the existence of a causal role played by subjective wellbeing in these domains, considering also studies of associations, where causality can be difficult to determine statistically. While several authors have already explored this evidence (e.g. De Neve et al. 2013; Quick and Abdallah 2015), the evaluation of these co-benefits has not been the focus of much attention-at least not in a comprehensive way. From the policy perspective, to ensure the appropriate allocation of resources towards subjective wellbeing, it is important to be able to value the overall benefits of enhanced happiness in monetary terms. This enables decision makers to compare the benefits of subjective wellbeing-based actions against those for other policy objectives. The second objective of the paper is to review the methods commonly used or developed in the literature to value these outcomes in monetary terms.

The paper is organised as follows: Sect. 2 clarifies the concept of subjective wellbeing and the importance of subjective wellbeing evaluations for policy makers. Section 3 reviews the literature analysing the link between subjective wellbeing and life outcomes. Section 4 focuses on evaluation methods used to place a monetary value on these outcomes. The last Section draws conclusion.

\section{Defining Subjective Wellbeing}

The attention and interest in subjective wellbeing shown by individuals and policy makers has gone hand-in-hand with the developments made in wellbeing research in the last decades. While everybody has an idea of what subjective wellbeing is and why it is valuable for himself, it is much more difficult to formulate a tangible definition of it (e.g. Dodge et al. 2012). The abstractness of the mental states that define subjective wellbeing is in 
fact inherently more difficult to explain and quantify than observable measures of objective wellbeing, such as years of schooling, presence of disabilities, or number of social interactions.

Following the developments in the psychological and economic literature (e.g. Diener et al. 1985, 1999, 2003; Kahneman and Krueger 2006; Dolan and White 2007), it has been suggested (Dolan and Metcalfe 2012; Hicks et al. 2013; O'Donnell et al. 2014) that to fully measure and understand individuals' subjective wellbeing, researchers and policy-makers should take into account three components: an "evaluative" or cognitive dimension, reflecting overall life satisfaction; an "eudemonic" dimension, reflecting sense of life purpose; and an "emotional" dimension, including both positive affective states, such as happiness and joy, and negative affective states, such as sadness and worry. The latter distinction has been shown to be important, as positive and negative emotions appear to be independent from each other (Diener and Emmons 1984; Diener et al. 1995), and, as such, they are not simply "the opposite ends of a continuum" (Cohen et al. 2003, p. 652).

Despite these distinctions, the terms life satisfaction, happiness and subjective wellbeing are often used interchangeably, and we do so in this paper. Although happiness is a central component of subjective wellbeing, it refers to the affective element of subjective experience. It is also important to stress that the feeling of happiness in contrast to having all the things that should theoretically make someone happy (e.g. money, good health) is the difference between objective and subjective wellbeing.

Interestingly, objective and subjective wellbeing indicators do not always go hand-inhand. The development of the economic field commonly referred to as Happiness Economics (Easterlin 2001, 2003; Layard 2005; Frey and Stutzer 2005; Dolan and White 2007) has in fact pointed out the existence of two substantial problems in wellbeing analysis: adaptation to current life circumstances and changing aspirations, The first refers for example to the case of married people who experience only a temporary increase in happiness following marriage (Lucas et al. 2003); the second refers to the fact that aspirations tend to change with income: an increase in income drags also an increase in aspirations which, in turn, may leave life satisfaction unaffected (Easterlin 2001, 2003). The latter seems to suggest that beyond a certain level, income and wealth fail to increase happiness and life satisfaction any further. Although more recent research has at least partly questioned the validity of these conclusions (e.g. Hagerty and Veenhoven 2003; Veenhoven and Hagerty 2006), this of course poses significant challenges to traditional financial measures of successful policy such as GDP and explains why subjective wellbeing is gaining traction as an alternative measure of prosperity.

The increasing interest in measuring subjective wellbeing at the national level and in policies targeting citizens' happiness (e.g. Helliwell et al. 2013; O'Donnell et al. 2014; Ura et al. 2012) implies that, to guarantee the appropriate allocation of resources towards subjective wellbeing, it is important to be able to value the overall benefits of enhanced happiness in monetary terms. This enables a clear comparison with the costs of interventions, and enables decision makers to compare the benefits of subjective wellbeing-based actions against those for other policy objectives. Robust valuation is central to cost-benefit analysis and to avoid undervaluing policies that promote non-market services such as volunteering which are not obviously reflected in GDP. 
Table 1 Empirical evidence of the co-benefits of wellbeing

Co-benefit dimension Empirical evidence of key linkages between subjective wellbeing and the following:

Health

Mortality (4-10 additional life years)

Prevention of new diseases (particularly stroke, ischemic heart disease, cold, pregnancy outcomes)

Survival from illnesses (mixed results, depending on seriousness of illness)

Doing physical exercise (in turn having a protecting effect against development of illnesses)

Social

Criminal and antisocial activities: higher delinquency is associated with lower subjective wellbeing levels

Prosocial behaviours: blood donation, voluntary work and money to charities

Social activities: more time spent with other, more quality time, higher enjoyment of social interactions

Employment

Lower levels of absenteeism and work turnover

Better worker performance in terms of manager assessments, income and productivity

Education Better educational achievements: better results in Key Stage tests and GCSEs exams

Environment Environmental-friendly household behaviours

More money to charities for environmental purposes

\section{Empirical Evidence of the Link Between Wellbeing and Life Outcomes}

Improving subjective wellbeing can have a number of impacts on individuals and society, and these will be reviewed in this section. Table 1 above presents a summary of findings.

Our main focus is on studies exploring the existence of a causal effect of subjective wellbeing on different life outcomes. Nevertheless, the estimation of a causal effect in this research field is not straightforward: the causal path between happiness and life outcomes is in fact likely to run in both directions. It has been shown for example that higher subjective wellbeing levels give the confidence and motivation to do better at school (see for example Gutman and Vorhaus 2012), while feeling stressed and unhappy often leads to adverse health practices (Grant et al. 2009). However, at the same time, doing well in our lives makes us feel happy and more satisfied.

Given the existence of a reciprocal relationship between subjective wellbeing and life outcomes, empirical studies aiming at exploring these relationships need to address this methodological issue if they wish to estimate causal effects rather than only correlations.

An appropriate method is based on representative sample surveys following individuals over time, and which allow to control for the level of subjective wellbeing at some point earlier in time, together with another set of confounding factors. This approach allows to minimise the reverse causation problem (i.e. being unhappy is also the result and not just the cause of having low health or employment outcomes). This is for example the approach followed by De Neve and Oswald (2012) in a study on the effect of subjective wellbeing on earnings. Also Gutman and Vorhaus (2012) use longitudinal data to analyse the relationship between child emotional wellbeing and future performance at school, while Thoits and Hewitt (2001) carry out a similar exercise on engagement in prosocial activities, controlling for baseline happiness and prosocial activities engagement. Several other examples come from the health literature. Ostir et al. (2000), Moskowitz et al. (2008) and Wiest et al. (2011) for example analyse mortality levels using longitudinal data where life satisfaction and affect was collected at baseline, together with other indicators of health and lifestyle 
which represent other potential confounding factors. A similar approach has been followed by Ostir et al. (2001) on the analysis of stroke risk in a 6-year follow-up study, and by Bush et al. (2001) in a study focusing on survival rates after stroke controlling for depression symptoms measured at hospital admission.

Another appropriate approach for the measurement of a causal relationship between subjective wellbeing and life outcomes come from experimental studies, in which the emotional state of the participants is exogenously affected in order to rule out any confounding factor. Cunningham (1988) carries out "mood induction" experiments, where joy and depression were induced using statements with a positive or negative message projected on a screen for a few seconds. Oswald et al. (2015) instead uses short videos and treats including candy and drinks to analyse whether mood affects productivity. Along similar lines, Challen et al. (2011) analyse the effect of the UK Resilience Programme (a programme aimed at developing children psychological wellbeing and carried out in a number of Local Authorities in the UK) and use longitudinal data to compare the performance of children who underwent the programme with the performance of those who did not. This review mainly includes longitudinal studies, which are more common than experimental studies in this field of research. However, in the case where no causal evidence is available, crosssectional studies are considered (e.g. Caldwell et al. 2010; Buunk et al. 2016 on life satisfaction and engagement in criminal behaviour; and Sulemana 2016 on subjective wellbeing and environmental behaviours). These studies do not fully address the causality issue, ending up measuring mainly correlations among variables rather than causal relationships. It should be noted that the main aim of these studies is not to estimate causal relationships, but rather to give a descriptive picture of these relationships.

\subsection{Health}

The relationship between health status and subjective wellbeing has probably been the most investigated, given the central position health has in our life. ${ }^{1}$

Given the multidimensional nature of health, the literature assessing the link between health and subjective wellbeing has focused on different health outcomes (Howell et al. 2007). In a review of the literature, Pressman and Cohen (2005) distinguish among studies examining the effect of subjective wellbeing on "longevity", "morbidity", "survival", "selfassessed health status" and "severity of diseases". Even the very perception of pain may be influenced by emotional style.

A common finding in the scientific literature analysing the link between subjective wellbeing and physical health is that the positive effect of subjective wellbeing and positive emotions is independent from the harming effects of negative emotions. For example, in an analysis on mortality carried out by Steptoe et al. (2015), the positive effect of positive indicators of subjective wellbeing on health is confirmed even after controlling for symptoms of depression. This result is supported also by the work by Mukuria et al. (2015) which analyse and compare several subjective wellbeing measures (looking at both single items and composite scales) using correlations and factor analysis. Mukuria et al. find a strong correlation between different subjective wellbeing measures, this being higher among positive measures. Their results from factor analysis suggest that positive and

\footnotetext{
1 Complete reviews of this literature can be found in De Neve et al. (2013), Diener and Chan (2011), Rasmussen et al. (2009), Veenhoven (2008), Chida and Steptoe (2008), Howell et al. (2007), Cohen and Pressman (2006), Pressman and Cohen (2005), Lyubomirsky et al. (2005).
} 
negative items are linked to different latent constructs, which are only weakly correlated. This suggests that positive and negative emotions are not simply "the opposite ends of a continuum" (Cohen et al. 2003, p. 652) and therefore can have an independent effect from each other.

Moreover, the literature commonly recognised that there may be a simultaneous relationship between subjective wellbeing and health (Howell et al. 2007; Chida and Steptoe 2008; Diener and Chan 2011) but this issue is not always appropriately addressed in empirical studies, in terms of study design and empirical strategy.

\subsubsection{Mechanisms Explaining the Health-Happiness Linkage}

With regards to the mechanisms through which subjective wellbeing can affect health, the literature has identified several possible pathways (Ong 2010). ${ }^{2}$ First, it has been shown that individuals with higher levels of subjective wellbeing are more likely to have a healthier lifestyle. Higher life satisfaction levels are found to be associated with not smoking, doing more physical exercise, using solar screen and eating healthy (Grant et al. 2009), improvements in sleep quality (Steptoe et al. 2008; Cohen et al. 2003), and higher adherence to treatment regimes (Pressman and Cohen 2005, p. 957).

The second mechanism explaining the effect of subjective wellbeing on health is represented by the biological and physiological responses of the human body to life satisfaction. Some studies have found evidence that higher levels of happiness are associated with lower levels of cortisol (Cohen et al. 2003), and, more generally, with better neuroendocrine, inflammatory, and cardiovascular responses (Steptoe et al. 2005) which can increase resistance to illness (Ong 2010).

Third, a psychological pathway also exists. Fredrickson and Levenson (1998) and Fredrickson et al. (2000) suggest that positive emotions can offset ("undo") the negative reactions generated by negative emotions. Furthermore, Fredrickson (2001, p. 10) suggests that positive emotions can help people increasing their "personal resources" and "psychological resilience" with long-term effects on a number of life outcomes. ${ }^{3}$

In the following we will review studies focusing on the effect of subjective wellbeing on mortality, health behaviours, prevention of new diseases, and survival from serious illnesses.

\subsubsection{Mortality}

A large part of the literature has analysed the link between subjective wellbeing and mortality, with happier people being found to live longer. However, it is difficult to generalize these results, as they come from studies carried out using different wellbeing measures, statistical techniques, as well as focusing on different populations (Veenhoven 2008; Diener and Chan 2011).

In a recent review of this literature, Diener and Chan (2011) quantify the effect of subjective wellbeing on mortality in 4-10 additional life years, when comparing individuals with high levels of subjective wellbeing with people with low levels. Diener and Chan also report the results of a meta-analysis carried out by Howell et al. (2007), suggesting a 6-year

\footnotetext{
2 See also Boehm and Kubzansky (2012), Pressman and Cohen (2005), Diener and Chan (2011), KiecoltGlaser et al. (2002), De Neve et al. (2013), Sabatini (2014) and Steptoe et al. (2005).

3 See also Quick and Abdallah (2015) for a discussion.
} 
difference in longevity for individuals with two standard deviation difference in subjective wellbeing.

It is important to stress the fact that in examining this relationship, most of these studies have taken into account also the individuals' health practices, such as physical exercise, smoking and drinking habits. This demonstrates that happiness affects health directly, not only via a healthier lifestyle.

A particularly interesting result emerging from this literature is that the protective effect of happiness is particularly felt by the elderlies-although it should be pointed out that some studies have shown the importance of happiness on mortality also for the general adult population (e.g. Lawrence et al. 2015).

In two distinct follow up studies using data for the US (Moskowitz et al. 2008) and Germany (Wiest et al. 2011), positive affect is found to significantly decreases risk of death among individuals aged over 65, even controlling for negative affect and lifestyle. The results of these two studies also suggest that for younger adults the relationship between subjective wellbeing and mortality is mainly mediated by physical exercise (with happier individuals living longer thanks to higher levels of physical exercise).

Along these lines, other studies have measured the impact of subjective wellbeing on mortality risks among elderlies. Steptoe et al. (2015) use ELSA (English Longitudinal Survey for Ageing) data on elderlies and show a 30\% lower risk of death for the highest respect to the lowest subjective wellbeing quartile over a 8-year period. Similarly, Steptoe and Wardle (2011) find a 35\% lower risk of death using the ELSA sub-sample that completed the Ecological Momentary Assessment on the day before the survey. This has the clear advantage of having several "real-time" assessments of emotional states, rather than only a recollective one.

Ostir et al. (2000) analyse a sample of Mexican-American aged 65-99 followed over a 2 -year period finding that a high positive affect score reduces mortality risk, this being only partially mediated by medical conditions at baseline.

Some studies also show a stronger association between subjective wellbeing and mortality among healthy individuals than among non-healthy. As suggested by Veenhoven (2008), "happiness does not cure illness but it does protect against becoming ill" (p. 449). Among others, Xu and Roberts (2010) examine longitudinal data for the Alameda County in California showing that an increase in subjective wellbeing (measured using several indicators) is associated with lower mortality, this association being much stronger among healthy individuals than among the non-healthy.

An interesting line of research focuses on how the eudemonic dimension of subjective wellbeing, i.e. sense of life purpose, can have an effect on health outcomes and mortality. These studies typically use longitudinal data in order to link these outcomes to previous life purpose as well as controlling for a set of confounders at baseline. In a 14-year followup study for the US, Hill and Turiano (2014) find that life purpose is associated with a significantly lower risk of death ( 0.85 hazard ratio), even controlling for other affective indicators of wellbeing. This confirms the suggestion that different wellbeing indicators are independent from each other. The analysis by Tanno et al. (2009) uses data for Japan and suggests that both men and women with sense of life purpose are less likely to die from any cause as well as from cardiovascular diseases in different follow-up intervals. Koizumi et al. (2008) find lower mortality risk from cardiovascular diseases, but only for men, in another 15-year follow-up study for Japan.

Using longitudinal data collected from elderly people in a residential care setting in Japan over a 12-year period and controlling for a set of confounders at baseline, Mori et al. (2017) show that feeling of life's worthwhileness halves the risk of developing disabilities 
hindering daily life activities. Similar conclusions are also found by Boyle et al. (2010) using data for the US and looking at limitations in daily life activities and mobility.

\subsubsection{Healthy Behaviour}

As already pointed out, subjective wellbeing can result in increased exercise and healthier lifestyle, this leading to better health outcomes (Reiner et al. 2013). Several studies have analysed the relationship between subjective wellbeing and health behaviours. Grant et al. (2009) use information collected on young adults in the International Health and Behaviour Study and find for example that higher subjective wellbeing levels are associated with higher likelihood of being non-smokers, of doing physical exercise, of using sun protection and eating more healthy. Similarly, Allgöwer et al. (2001) find that depression is correlated to having number of negative behaviours in a cross-country sample of university students, such as being a smoker, doing little physical activity, having poor sleeping habits and not using seat belts. The Copenhagen City Heart Study (Schnohr et al. 2005) finds a significant association between level of physical exercise (categorized as "low", "moderate", "high" or "joggers") and life dissatisfaction (being not satisfied vs. being either very or somewhat satisfied), with lower probability of being dissatisfied among more active individuals. This may be related to the fact that the physiological adrenaline effect associated with physical exercise may have not only a transitory effects on subjective wellbeing and therefore last longer than the physical exercise itself. ${ }^{4}$

It should pointed out that the mechanism behind these associations is likely to be quite complicated and probably better described in terms of a simultaneous relationship between subjective wellbeing level and type of lifestyle. Such evidence is found for example in the analysis of the role played by physical activity in the risk of developing depression symptoms by Da Silva et al. (2012).

\subsubsection{Prevention of New Diseases}

A number of studies have focused also on the direct effect of subjective wellbeing on the development of new diseases. Some research has assessed the link between happiness and cardiovascular diseases, such as stroke and heart attack.

Ostir et al. (2001) analyse the link between positive and negative subjective wellbeing states and the risk of stroke over a 6-year follow-up, controlling also for blood pressure, smoking habits and BMI. Results suggest a protective effect of positive affect, while no significant effect is found for negative affect. Negative affect has instead been found to increase stroke incidence in a study by Everson et al. (1998), showing that depressed persons (i.e. having at least 5 out of 18 symptoms of depression) are 1.5 times as likely to experience a stroke compared to non-depressed persons, after accounting for health practices and presence of other diseases.

Similar results are found in a study on the incidence of ischemic heart disease (IHD), showing that depressed subjects have 1.6 times the risk of experiencing nonfatal IHD and 1.5 times the risk of experiencing fatal IHD compared to subjects with no depression (Anda et al. 1993).

${ }^{4}$ We thank an anonymous referee for this suggestion. 
Some research has also analysed the link between subjective wellbeing during pregnancy and birth outcome, finding that prenatal depression is associated with premature birth (Orr et al. 2002), lower birthweight, alterations in the newborn's biochemical and physiological profile (Field et al. 2006), as well as live birth delivery and multiple gestation in case of IVF (Klonoff-Cohen et al. 2001).

In a well-known experimental study by Cohen et al. (2003), positive subjective wellbeing is found to be protective against the development of a cold, and, distinguishing between three categories of positive emotional style, a risk ratio of 2.9 is found for those in the lowest category respect to those in the highest.

\subsubsection{Survival}

The literature has also analysed the effect of subjective wellbeing on survival for people suffering from certain illnesses or chronic conditions. Pressman and Cohen (2005) suggest that positive emotions can be beneficial for individuals affected by diseases characterised by low mortality rates, while in case of advanced or more dangerous diseases, individuals with high levels of positive emotions may be too optimistic about their real chances of overcoming the illness, this leading to lower survival due to inappropriate lifestyle and lower treatment persistence.

Subjective wellbeing is found to reduce mortality and increase survival for example among patients with diabetes (Moskowitz et al. 2008) and among people with chronic conditions (Howell et al. 2007). Bush et al. (2001) suggest that depression increases mortality after myocardial infarction. Moskowitz (2003) also finds that positive affect reduces mortality among HIV + men. This result may be mediated by better care and higher adherence and persistence to antiretroviral therapy in patients with higher positive affect (Carrico and Moskowitz 2014).

\subsection{Social Outcomes}

The literature has found an association between subjective wellbeing and a number of social behaviours (for reviews, see Aspinwald 1998; Lyubomirsky et al. 2005; De Neve et al. 2013; Quick and Abdallah 2015). In this section, we will focus on the empirical evidence showing a link between life satisfaction on one side and criminal behaviour, prosocial behaviour and social interactions on the other side.

\subsubsection{Prevention of Criminal and Antisocial Activities}

A number of studies have investigated the linkage between crime and subjective wellbeing - with the focus being largely on the impacts of crime on wellbeing. For example, Cornaglia et al. (2014) use data for Australia and conclude that an increase in violent crime in an area leads to a significant reduction in community wellbeing, this being much higher than the effect of property crime. Similar results are found also for Germany by Krekel and Poprawe (2014).

In this study, we are more interested in the impacts that subjective wellbeing can have on crime rates. A number of studies have examined the determinants of the crime rate, but few have focussed on subjective wellbeing. However, elements of the determinants of life satisfaction also arise in the studies on the determinants of crime. For example, in the case of German municipalities, factors such as employment, the divorce rate, poverty and 
inequality are shown to be important in determining the crime rate (Buettner and Spengler 2003).

Some papers have also examined the link between life satisfaction and criminal behaviours, with a particular focus on adolescents and young adults. Caldwell et al. (2010) analyse for example a sample of young Mexican-American (aged 11-17) and find a negative correlation between their degree of delinquency (capturing both their opinions and their actual engagement in anti-social activities) and their level of self-esteem and psychological wellbeing, though only the former result is statistically significant. Buunk et al. (2016), examine life satisfaction in a sample of Spanish criminal offenders aged 16-24 and find that life satisfaction is lower among those held in correctional institutions than those on probation. According to the authors, however, type of punishment is not casual and the rationale behind this may be to avoid recidivism among individuals with lower levels of subjective wellbeing.

\subsubsection{Prosocial Behaviours}

The empirical research has shown that happy people are more willing to do something for others, such as to work for charities or to engage in other types of voluntary work. In particular, the literature has shown that happy and satisfied people are more likely to be blood donor and to donate money to charities (Priller and Schupp 2011), devote more hours to voluntary activities (Thoits and Hewitt 2001; Griep et al. 2015) and also engage in an higher number of types of unpaid voluntary activities (Oishi et al. 2007).

A number of these studies use longitudinal data to detect causal relationships, and it is also widely recognised that volunteering and subjective wellbeing are linked in a simultaneous relationship (Liu and Aaker 2008; Chiang-Ming et al. 2014; Aknin et al. 2012; Thoits and Hewitt 2001), helping people is beneficial, and not just for those receiving assistance.

\subsubsection{Social Relationships and Social Activities}

A large empirical research body has investigated the link between subjective wellbeing and social interactions. However, given the little use of experimental and longitudinal studies in this field, causality issues still need to be fully investigated. It has been shown that happy people like spending time with others; however, at the same time, spending time with other people makes us happy. Also, the literature has suggested that people enjoy spending time with happy and extrovert people (Mehl et al. 2010), while contact with depressed subjects can have a detrimental effect on our mood as well (De Neve et al. 2013).

A relevant paper in this area is represented by the experimental study by Cunningham (1988) in which the author exogenously influences subjects' feelings using a "mood induction" technique to assess whether being in a good or in a bad mood can have an influence on type of activities we engage in. Cunningham observes that induced joy increases the willingness to engage in social, vigorous and leisure activities with respect to the neutral group. The opposite is found for the subjects assigned to negative mood induction. It is also shown that this difference is partially the result of a different perception of the individuals in the two groups about the effort needed to carry out energetic activities as well as a different perception in terms of the positive consequences of engaging in social activities.

A large literature has focused on the link between subjective wellbeing and the quality and quantity of social relationships, making wide use of data collected on university 
students. Diener and Seligman (2002) distinguish between three levels of happiness (very high/medium/very low) and show that "very happy" subjects rate the quality of their social contacts very highly, spend significantly more time with other people and less time alone. Similar results are also found by Berry and Hansen (1996) with reference to the role of "positive affect and extraversion". Waugh and Fredrickson (2006) analyse a sample of college freshmen and show that positive emotions help developing better relationships with roommates, both in terms of closeness and in terms of deeper understanding. Mehl et al. (2010) find that individuals with higher levels of happiness and satisfaction spend more time talking to others and also have deeper conversations. In particular, when distinguishing between individuals in the highest and in the lowest level of happiness, the former are found to spend twice as much time in deep conversations respect to the latter.

Also Lucas et al. (2008) find a positive association between having positive feelings and time spent in social relationships with friends and family member. However, they analyse the relationship going from social interactions to subjective wellbeing. In particular, they use a structural equation model to investigate the relationship between extraversion, positive affect and engagement in a number of social activities for a group of college students. Results show that extraversion increases positive affect directly, as well as indirectly, through increased time spent with family and friends and time spent helping others.

\subsection{Employment}

The literature has highlighted that subjective wellbeing can have a positive impact on several labour market outcomes, for example in terms of better work history, increased income and productivity and lower job turnover (reviews of this literature can be found in Lyubomirsky et al. 2005; Boehm and Lyubomirsky 2008; Barsane and Gibson 2007; De Neve et al. 2013; Quick and Abdallah 2015). This may be the result of good social relationships. However, positive emotions seem to affect also the problem solving process thanks to increased creativity and better cognitive capabilities (Isen et al. 1987; Isen 2001; Rego et al. 2014; Paterson et al. 2016; Yuan 2015). In turns, this can influence also the bargaining process and the resolution of conflicts (Forgas 1994; Baron et al. 1990; Kanske and Kotz 2011; Morris and Keltner 2000).

\subsubsection{Turnover and Absenteeism}

The relationship between subjective wellbeing, absenteeism and voluntary job withdrawal has been analysed in several studies. Job withdrawal and absenteeism are the likely result of dissatisfaction with the job one is doing. A meta-analysis carried out by Bowling et al. (2010) investigates the relationship between subjective wellbeing and job satisfaction and suggests that the two concept are linked in a simultaneous relationships: higher levels of job satisfaction increase life satisfaction, and higher levels of life satisfaction positively affect job satisfaction. Moreover, although both effect are statistically significant, the latter effect prevails.

Along these lines, Credè et al. (2007) examine a large sample of workers holding nonacademic positions in a university and estimate a structural equation model on the determinants and consequences of job satisfaction. Their results show that individual dispositional characteristics, including personality traits and emotional states, influence job satisfaction, and this in turn reduces job withdrawal. These results are in line with Waters and Roach 
(1971), which find a significant correlation between the degree of satisfaction with the job and both absenteeism and job turnover measured 1 year later.

Pelled and Xin (1999) collect data on a sample of employees and examine the extent to which subjective wellbeing at baseline influences hours of work absence and job withdrawal 5 months later. Their findings suggest that, even controlling for satisfaction in the workplace, positive emotional states predict lower hours of absence while, to a lesser extent, negative emotions predict both higher absence and job withdrawal. Similarly, Iverson and Deery (2001) analyse the role of positive and negative affect on a number of workrelated behaviours in a sample of bluecollars working in the automotive sector: absenteeism, arriving late and leaving early. Controlling also for job satisfaction, absenteeism is found to decrease with increasing positive affect.

\subsubsection{Work Performance and Productivity}

Recent research suggests that there is a significant linkage between happiness and worker productivity. For example, Oswald et al. (2015) use a range of experiments to test the relationship in a lab based setting and find that those who undergo what were framed as "happiness treatments" (in this case the enjoying of a comedy movie clip or provision of chocolate, fruit and drinks) respond with a $10-18 \%$ increase in productivity.

Some studies have analysed the prospective effect of subjective wellbeing on the performance of the worker measured later in time. Staw et al. (1994) show that positive affect predicts the performance of the worker approximately 18 months later, both in terms of wage level and manager assessment. This is a composite measure capturing several characteristics of the worker, such as creativity, sociability and quantity and quality of work. More recently, Peterson et al. (2011) specifically address the issue of causality in the relationship between positive psychological wellbeing and work performance in a sample of 179 employees working in the financial sector. Work performance is measured using manager performance evaluation and sales data. Using data collected in three different moments in time, the authors find evidence that subjective wellbeing determines work performance, and not vice versa.

A relevant study by De Neve and Oswald (2012) uses data drawn from the National Longitudinal Study of Adolescent Health to analyse the causal relationship between happiness and income in the US. The data collect information on subjective wellbeing at age 16, 18, 22 and 29 together with income at age 29. Two different model specifications show that higher levels of wellbeing experienced throughout life are associated with higher future earnings. Moreover, it is found that the effect of wellbeing on income is partially mediated by the fact that happy people are more likely to get a university degree, to find a job and to show higher self-esteem. Estimates suggest that this indirect effect of subjective wellbeing counts for about $68-78 \%$ of the total effect.

Bryson et al. (2015) use data drawn from the Workplace Employment Relations Survey to analyse the association between job satisfaction and work performance in the UK. Although this study does not focus on the effect of overall life satisfaction, it is quite relevant as it investigates the issue of causality by analysing the panel component of the survey. In the analysis, job satisfaction is a variable ranging from -18 to +18 covering several aspects of the job, while work performance is a variable ranging from 0 to 9 capturing "financial productivity", "labour productivity" and "quality of product and service". The authors show that a 1-point increase in job satisfaction leads to a 0.7 points increase in the 
worker's performance. Moreover, the analysis of the longitudinal data rules out the existence of reverse causality between job satisfaction and performance.

\subsection{Education}

A number of wellbeing interventions have been conducted in educational settings. Some wellbeing interventions focus on students who are "at risk" of exclusion or who may benefit from increased confidence and motivation. Students may also benefit from improved health and wellbeing in terms of educational attainment, and vice versa. It has been in fact pointed out that depression and other mental problems are linked in a simultaneous relationship with poor academic performance (Patel et al. 2007). Strong interrelationships between health, wellbeing and school outcomes exist, as it has also been suggested in a recent review of the literature by Public Health England (2014).

The relationship between children subjective wellbeing and academic outcomes is a complicated issue, as the wellbeing of children at school reflects not only their life satisfaction, but also social and behavioural elements of their life (Gutman and Vorhaus 2012). Gutman and Feinstein (2008) analyse for example child wellbeing using several indicators. These include emotional and mental health indicators, such as suffering from depressive symptoms and child "locus of control", i.e. his perception of being able to control and to influence what happens in his life and his school outcomes. Gutman and Feinstein point out that also social behaviours are relevant child wellbeing indicators, such as the quality of the interactions with peers (including experiences of bullying or being bullied), the interaction with teachers as well as school enjoyment.

\subsubsection{The Empirical Evidence on the Role of Life Satisfaction and Emotional Wellbeing}

The relationship between life satisfaction and educational outcomes has been analysed in several studies. For example, Gilman and Huebner (2006) collect data on a sample of US students enrolled in grades 6-12, and distinguish between three levels of life satisfaction. Descriptive statistics suggest that students with higher wellbeing are more likely to perform better at school in terms of engagement in extracurricular activities and grades. Similarly, Leung and Leung (1992) find that life satisfaction is significantly correlated with perception of academic competence when analysing a sample of students aged 11-16 in Hong Kong. As for the UK, the research shows that life satisfaction at age 19 is positively correlated with previous education achievements (Department for Education 2011). In particular, $29 \%$ of young people that have achieved at least five GCSEs awarded $\mathrm{A}^{*}-\mathrm{C}$ grades are "very satisfied" with their life and 53\% are "fairly satisfied with their life". This is against respectively 25 and $46 \%$ of young people with lower educational achievements. The same study also finds that young people who are still in education at age 19 are more likely to be "very satisfied" with their life $(32 \%)$ with respect to people who are the same age but in employment (25\%) or neither in employment nor in education (18\%). These figures obviously suggest only correlations: a higher level of life satisfaction may be the result of good school achievements and of a stimulating academic path, and at the same time higher subjective wellbeing gives the motivation to do better at school and the confidence to embark on tertiary education. Moreover, life satisfaction is measured at age 19, while GCSEs are taken at age 16 . 
Other emotional and psychological wellbeing indicators play an important role in children educational development, which has been extensively analysed by the literature. The meta-analysis carried out by Haney and Durlak (1998) suggests that some psychological wellbeing interventions can have a greater effect than others in improving children performance at school. In particular, their study finds that children particularly benefit from interventions aimed at enhancing their self-esteem and self-concept. Challen et al. (2011) analyse the effect of the UK Resilience Programme - a programme aimed at developing children psychological wellbeing. The authors collect data for students in three different Local Authorities and follow them over time. The study shows that students benefit from the programme and, compared to children that did not undergo the programme, they perform better, especially in English, both in the year of treatment and the year after.

Panel data drawn from the Avon Longitudinal Study of Parents and Children are used by Gutman and Vorhaus (2012) to analyse the causal relationship between child emotional wellbeing - capturing the extent to which the child worries and is anxious about things that may happen in the future or have happened in the past-and his subsequent academic performance, measured in terms of value-added Key Stage test scores. Comparing children with the highest level of emotional wellbeing at age 7 (i.e. having no problems) with children with the lowest level of emotional wellbeing (i.e. having a lot more problems than other children), the former have a better performance at age 11 in Key Stage 2, with higher value-added from Key Stage 1 to Key Stage 2.

\subsubsection{The Empirical Evidence on the Role of the Relationship with Peers and of School Enjoyment}

Several studies have focused on child satisfaction with social relationships with peers, this being considered an important driver of school attachment and consequent school performance (Public Health England 2014). This is a relevant issue for children, given that a research by Gutman and Brown (2008) using data from the Avon Longitudinal Study of Parents and Children has shown that around 25\% of children aged 8-10 experience poor relationships with peers.

Flook et al. (2005) collect longitudinal data on a sample of primary school children followed over 3 years, including information on performance in math and reading and the quality of the social relationship with the other students. Their findings show that low levels of social relationships have long-term negative effects on school performance and explain around 25\% of school performance. Along the same line, Delgado et al. (2016) carry out an analysis focusing on Latin American adolescents living in the US. Using a Structural Equation Model, they find that having close friends increases the sense of school belonging, this having in turn a positive effect on school attainment.

The psychological wellbeing of children at school has been recently analysed by Gibbons and Silva (2011) using data of the Longitudinal Study of Young People in England. The study concludes that a positive association exists between wellbeing at school and academic achievement, these being measured in terms of happiness at school, teachers' appreciation and enjoyment of lessons on one side and pupil and school value-added from Key Stage 2 to Key Stage 3 on the other side. An empirical analysis by Pittman and Richmond (2007) shows that also college students with higher sense of attachment to university tend to perform better and to be more confident in their academic abilities. 
However, the literature results are not univocal. Among others, Gillen-O'Neill and Fuligni (2013) find that school attachment significantly affects school enjoyment and sense of school usefulness, but it little explains school performance.

Foreman-Peck and Foreman-Peck (2007) analyse data drawn from the Longitudinal Study of Young People in England to study the extent to which being bullied can harm student performance. In particular, the authors distinguish between different types of child victimization (i.e. being hit, being called offensive names, or having money or other things stolen) and between bullying experiences reported by the parent and by the student himself. Student performance is measured in terms of pupil's value-added from Key Stage 2 to Key Stage 3. Results suggest that bullying experiences reported by the parents have a significant and negative effect on academic achievements. Vignoles and Meschi (2010) use the same dataset and find that being bullied has a weak but long-term negative effect on scholastic achievements, this being measured in terms of GCSE scores.

\subsection{Environment}

To the best of our knowledge, the empirical evidence has mainly focused on the effect that the environment can have on individual subjective wellbeing (e.g. Rehdanz and Maddison 2008; Cunado and de Gracia 2013), while the literature analysing the positive impact of subjective wellbeing on the environment is quite scant. It has been shown for example that prosocial oriented individuals are more likely to have a greener lifestyle (Cameron et al. 1998). Given that the literature has shown an association between wellbeing and social behaviour, one may claim that high levels of subjective wellbeing may result also in changes in lifestyle and environmental behaviours. More recently, Sulemana (2016) has concluded that happier people are more likely to be in favour of giving up money for environmental purposes in both developed and Sub-Saharan African countries. Similarly, Duroy (2008) finds evidence of a positive association between subjective wellbeing and a number of activities connected to the environment, such as choosing environmentally friendly household products, recycling and donating money to environmental organizations.

\section{Economic Valuation of Subjective Wellbeing and Life Outcomes}

Happiness and the life outcomes discussed so far are certainly very valuable for the individual. However, given that these are mainly non-marketed outcomes, one must rely on other methods to estimate their value. In the absence of market prices, a traditional approach to ascertain value is to assess decisions people make through revealed or stated preferences. Another approach is the "life satisfaction approach", which has been developed in recent years. This approach uses survey based methods to estimate changes in life satisfaction and, using the relationship between life satisfaction and income as a reference, it allows to value changes in provision of a range of non-marketed goods (HMT 2011; Fujiwara 2013).

It should however be highlighted that the use of the life satisfaction approach in the context of this research may be questionable and does not come without its problems. ${ }^{5}$ While our aim is to look at how and to what extent subjective wellbeing may positively affect a

${ }^{5}$ We thank an anonymous referee for pointing out this problem. 
number of objective life domains, the life satisfaction approach builds upon the opposite exercise: it bases itself on the evaluation of how the same life domains influence life satisfaction. The rationale underlying the use of the life satisfaction approach is in fact that the causal path between life outcomes and happiness runs only from the former to the latter, while we are interested in the empirical evidence in support of the opposite relationship.

Following this approach, HACT and Fujiwara have developed the Social Value Bank (see Fujiwara et al. 2014 for details). This tool offers robust and comparable estimates of the value a range of activities and outcomes across several life domains, such as employment, health, social activities and local environment. These estimates are produced using data from several national surveys and can be used in cost-benefit analysis.

The What Works Centre for Wellbeing is currently exploring the use of life satisfaction measures compared to the costs - in a way this is similar to the methods used by the UK National Institute for Health and Care Excellence (NICE) for decisions on treatment provision in the health setting, where a cost per Quality Adjusted Life Year is used to estimate whether a particular treatment is "cost-effective" or not.

In this section, we will reviews the methods that can be used to assign a price to subjective wellbeing and its co-benefits.

\subsection{Subjective Wellbeing}

Monetary valuation of subjective wellbeing is still in its relative infancy (Cox et al. 2012). The life satisfaction approach described above can be used to value several aspects related to subjective wellbeing. For example, according to the Social Value Bank, "relief from anxiety and depression" can be worth over $£ 36,000$ per year, while "feeling in control of life" over $£ 12,000$. Another method to value wellbeing described by Cox et al. (2012) is to compare a loss of subjective wellbeing with the development of severe mental health problem and use Quality Adjusted Life Year (QALY) weights assessed by health economists (Sainsbury Centre for Mental Health 2003). QALYs are one way economists use to estimate the varying types of health outcomes in a common metric - with a value of 1 indicating a year in full health and 0 indicating death. Taking the loss of QALYs from a severe mental health condition (0.352) and multiplying by the NICE Cost Effectiveness threshold of $£ 30,000$ gives a value of $£ 10,560$ per year for overall wellbeing. There is some evidence in the literature that children's health is value more highly than that of adults. OECD (2004) suggest that a factor of 2 should be applied — so this might imply a value of overall children's wellbeing of $£ 21,120$ per annum. Cox et al. (2012) further discuss what aspects of wellbeing should be considered for its valuation, suggesting to include evenly both personal (e.g. self-confidence and satisfaction) and social (e.g. feeling of trust and belonging) wellbeing aspects and that all these components should add up to $£ 10,560$.

\subsection{Health}

\subsubsection{Mortality}

A range of methods exist to value changes in mortality risk. These include transfer of values from existing studies using contingent valuation methods, where people are asked in a survey to state their willingness to pay to reduce particular risks (e.g. Alberini et al. 2006), or revealed preference methods, where for example wages and the relative mortality risks 
associated with different professions can be analysed. These studies derive either a value of a statistical life or, in some cases, can be used to attempt to derive a value of a life year.

One common metric to evaluate benefits to health is that of quality adjusted life years (QALYs). This brings together both mortality and morbidity outcomes in a common metric-so accounting for both changes in life expectancy and quality. This measure is used by NICE in evaluating the cost-effectiveness of outcomes-and seeing if a threshold for costeffectiveness is met ( $£ 30,000$ per QALY being a common "threshold"). To value QALYs in monetary terms, the social value of a quality adjusted life year can be used-work on valuing QALYs is less developed than that for valuing statistical lives, but some estimates do exist. For example, Mason et al. (2009) compare the value for life years and the value of QALYs and find that the QALYs may be worth between $£ 34,925$ and $£ 70,896$ and life years $£ 29,691-£ 57,569$.

\subsubsection{Increased Exercise}

Leading a healthy life carrying out physical activities on a regular basis is beneficial for the individual and the society both in terms of enhanced quality of life as well as in terms of reduction is the costs for health services. However, measuring the health benefits of increased exercise is not straightforward, as physical exercise carried out at different intensity levels may have a different impact on different types of illnesses. Some tools exist to derive economic values of the health benefits of increased exercise. The WHO-Europe (2014) have developed the Health Economic Assessment Tool (HEAT) to measure the health benefits of walking and cycling via estimation of effects on mortality. The MOVES tool $^{6}$ has instead been developed by Sport England to help estimate the return on investment for sporting activity. This tool helps in estimating the QALY gains and cost savings through avoided disease, accounting for the fact that physical activity can be more protective against some types of illnesses than others, and for the different treatment costs of different diseases. Beale et al. (2007) have instead analysed the relationship between level of physical exercise and perceived health using the Health Survey for England, estimating in this way the gains in QALY of increasing physical exercise for the adult population. Following this evaluation approach and assuming a value of $£ 20,000$ per QALY, White et al. (2016) evaluate that the QALYs gained through physical exercise carried out in natural environments in England may be worth over $£ 2$ bn a year. Along the same lines, Papathanasopoulou et al. (2016) suggest that increasing marine physical activity in the UK is worth between $£ 176 \mathrm{~m}$ and $£ 746 \mathrm{~m}$ a year.

\subsubsection{Health Service Use}

Health service use can be valued using "cost-of-illness" type approaches. For instance, in the UK the cost of one GP visit avoided thanks to improving subjective wellbeing can be valued at approximately $£ 45$ (Personal Social Services Research Unit 2015). This does not include drugs and other costs associated with illnesses.

\footnotetext{
${ }^{6}$ http://www.northyorkshiresport.co.uk/files/12339/guide-to-the-model-for-estimating-the-outcomes-andvalues-in-the-economics-of-sport.pdf.
} 


\subsubsection{Valuing Health Using the Life Satisfaction Approach}

The value of several health outcomes can also be estimated using the life satisfaction approach-although this might be a questionable approach to use in this case. The Social Value Bank developed by HACT and Fujiwara shows for example that being in good health may be worth $£ 20,141$ per year, stopping smoking around $£ 4000$ per year and overcoming depression problems even $£ 36,766$ per year. Doing regular physical exercise can be valued between $£ 3500$ and $£ 4200$ per year depending on the level of the activity.

\subsection{Social Outcomes}

\subsubsection{Economic Valuation of Criminal and Antisocial Activities}

Potential values that can be placed on changes in crime and antisocial behaviour include the cost of policing and the social impact of crime. Studies have attempted to value the impact of crime to society. For example the UK Home Office (2005—cited in Cox et al. 2012) estimate that the social impact of crime, reflecting the Physical and Emotional Impact on Direct Victims of different types of crime is around $£ 1480$ per crime incident. Instead, $£ 118$ is the cost per incident of antisocial behaviour-reflecting the lowest value of crimes for which the social impact has been calculated (theft—non vehicle).

\subsubsection{Economic Valuation of Voluntary Work}

Haldane (2014) points out that voluntary work is valuable at three different levels: for the "economic output" it produces through the unpaid work of the volunteers; for the "private" benefits the voluntary workers derive in terms of increased satisfaction with their life and also for example development of new skills; for the "social" benefits derived by the whole society.

Foster and ONS (2013) suggest that the economic value produced by volunteer work should be evaluated using the "replacement cost" approach, and they provide some figures for "professional", "clerical" and "personal" activities using the UK Annual Survey of Hours and Earnings. The life satisfaction approach or the "opportunity cost" approach should instead be used to value the "private" benefits of voluntary activities.

Using the life satisfaction approach to value voluntary work, Fujiwara et al. (2014) show that people engaging frequently in volunteering (i.e. at least once a month) estimate their activity at $£ 2357$ per year, while attending regularly voluntary organisations is valued $£ 1773$ per year. According to Haldane (2014) the private benefits of the entire voluntary sector could be worth $£ 40$ billion per year at the national level in the UK. However, the value of voluntary work is actually higher, as it affects not only the volunteers but also the life of all the individuals they get in contact with: he suggests a social multiplier between 2 and 10 for every pound invested in the sector.

\subsubsection{Economic Valuation of Social Relationships and Social Activities}

Fujiwara et al. (2014) have also estimated the value of social relationships using the life satisfaction approach. They show that being a regular member of a social group is worth on average $£ 1850$ per year, but with big differences by age group. Social relationships are particularly important for young people and people aged over 50. Following a similar 
approach, Powdthavee (2008) uses BHPS data to value the time spent with friends and non-cohabiting relatives. Using a panel data technique to control for fixed unobservable individual characteristics, Powdthavee finds that getting together with friends and relatives almost every day respect to "less than once a month (or never)" is worth on average $£ 85,000$ per year. Meeting friends less frequently-once or twice a week or once or twice a month-is estimated to be worth respectively $£ 69,500$ and $£ 57,500$ per year.

\subsection{Employment}

While the effect of subjective wellbeing on income can be measured directly, as it is expressed in monetary terms, monetarizing other productivity measures, such as manager evaluations of the worker's performance or job withdrawal is more challenging.

The Chartered Institute of Personnel and Development (CIPD 2010) estimates the average annual cost of absence per employee is $£ 600$ (median), this being much higher in the public (approximately $£ 900$ ) than in the private sector (£400). Allen (1983) values the cost of absence in terms of wage loss as well as productivity loss. As for wage loss, he estimates that a $10 \%$ increase in absence is associated with a 1.3-3.1\% decrease in wages, depending on industry and type of job. A similar increase in absenteeism would instead reduce productivity by $1.6-3.1 \%$, depending on the model specification.

According to CIPD (2009), the average cost of labour turnover may be around $£ 6100$ on average, Moreover, one should consider the time needed to fill a post, going from 6 weeks in the case of manual workers to 17 weeks for more senior positions.

Bevan (2010) highlights the significant range of benefits that can be derived from improved workplace satisfaction, including: reduced accidents at work, improved retention rates (with examples including BT’s work-life balance policy yielding a $£ 3 \mathrm{mn}$ saving in recruitment costs), higher labour productivity and greater employee resilience.

\subsection{Education}

In a study for Barnardos, Evans (undated) highlights the range of costs of exclusions. These include:

- Costs to the individual-with those being permanently excluded from schools being three times more likely to leave school with no qualifications and being more likely to be unemployed;

- Costs for the state: which includes:

- Costs to Local Education Authorities of alternative provision;

- Costs for social services and the criminal justice system;

- Costs for the NHS.

- Costs to the community, with anti-social behaviour leading to impacts.

\subsubsection{Increased Educational Attainment}

Increased educational attainment can be valued in a number of ways. It is common to distinguish between the "marginal" and "average" effect of education: the former looks at the return of an educational achievement which is hold as the highest attainment, the latter 
looks at its return regardless of whether this is the maximum educational level achieved (Hayward et al. 2014). The return to education is the result of both a wage and employment effect.

In a study by the British Department of Education, Hayward et al. (2014) use LFS data to estimate the productivity gain derived from higher educational achievements. The average effect on lifetime productivity from having achieved more than five good GCSEs is around $£ 60,000$. The marginal effect on the individual lifetime productivity of having 5-7 GCSEs at grades $\mathrm{A}^{*}-\mathrm{C}$ including English and maths compared to any lower achievement is around $£ 100,000$. It is around $£ 60,000$ if compared to being in possession of 3-4 good GCSEs. In a recent study for the Department for Education, Hunt and Vernoit (2014) estimate that such an improvement in GCSEs performance would lead to a return of $£ 1300$ million between 2010 and 2014 at the national level. Productivity estimates do not take into account the wider benefits of education.

Another recent study by Conlon and Patrignani (2015) of London Economics uses data from the British Cohort Study to focus on the returns to A-levels, distinguishing by gender and STEM versus Non-STEM subjects. Their findings suggest, among other results, that the marginal benefit of attaining an A level in a STEM subject awarded A-C is around $£ 7000$ per year for men, and $£ 4500$ for women.

\subsection{Environment}

There is a vast literature on the valuation of environmental change-with recent examples in the UK including the National Ecosystem Assessment, which used a mixture of methods from environmental economics to estimate the value of ecosystem services in the UK. Examples of different environmental changes that can be valued in monetary terms include:

- Changes in greenhouse gas emissions/carbon sequestration-which can be valued either using estimates of the "social cost of carbon" or market values for carbon. The UK government has moved towards using more the traded value of carbon in policy assessment. The short-term traded sector carbon values are presented in DECC (2015), which shows the current value of carbon to be between $£ 5$ and $£ 20.79 / \mathrm{tCO}_{2 \mathrm{e}}$ for emissions in 2015 and between $£ 39.23$ and $£ 117.68 / \mathrm{tCO}_{2 \mathrm{e}}$ for emissions in 2030;

- Changes in recreational provision - which can be valued using either studies that have used revealed preference methods (e.g. travel costs) or stated preferences (e.g. surveys using contingent valuation).

\section{Conclusions}

The measurement of subjective wellbeing has become increasingly important as society moves away from measures of GDP as the target for growth towards enhancing the benefit for society as a whole. Efforts to value subjective wellbeing to date have focussed on the estimation of the income compensation approach - where the amount of income needed to substitute for a decrease in subjective wellbeing is used. However, the co-benefits of increased subjective wellbeing have attracted less attention-with the benefits of subjective wellbeing through improved health, reduced antisocial behaviours, improved social relationships, improved productivity and improved environments getting less attention. This 
paper attempts to bring together the evidence on the co-benefits of subjective wellbeing and to provide the basis for the valuation of these benefits in monetary terms.

The literature is in its infancy-but important lessons and gaps can be identified. Relatively more has been done to estimate the impact on health than other co-benefits, especially in terms of increased longevity and lower incidence of diseases. Benefits have also been identified in terms of increased productivity, both in the workplace and in other settings, and in the social dimension. The literature is relatively more scant in terms of the impact of subjective wellbeing on the individual's tendency to delinquency or on his behaviour towards the natural environment.

Moreover the existing empirical evidence on the relationships between subjective wellbeing and the wider benefits to society is made up of quite heterogeneous studies. In a number of cases the empirical evidence comes from experimental studies, in which the subjective wellbeing of the individuals is exogenously influenced, or from longitudinal studies, where the same individual is followed over time and which also allow to control for a number of confounding factors-hence reducing their influence in the relationship. In other cases instead, given the use of cross-sectional datasets or the lack of appropriate empirical techniques, associations rather than causal relationships are measured.

Acknowledgements This study was carried out within the project "Valuing the health benefits of city well-being" (Project no. 132025) funded by Innovate UK. The authors would like to thank the participants to the WellWorth Consultation workshops held in Bristol on 7 April and 5 July 2016 for their valuable comments.

\section{Compliance with Ethical Standards}

Conflict of interest Happy City is a community interest company which works in the field of the measurement and valuation of wellbeing.

Open Access This article is distributed under the terms of the Creative Commons Attribution 4.0 International License (http://creativecommons.org/licenses/by/4.0/), which permits unrestricted use, distribution, and reproduction in any medium, provided you give appropriate credit to the original author(s) and the source, provide a link to the Creative Commons license, and indicate if changes were made.

\section{References}

Aknin, L. B., Dunn, E. W., \& Norton, M. I. (2012). Happiness runs in a circular motion: Evidence for a positive feedback loop between prosocial spending and happiness. Journal of Happiness Studies, 13, 347-355.

Alberini, A., Hut, A., \& Markandya, A. (2006). Willingness to pay to reduce mortality risks: Evidence from a three-country contingent valuation study. Environmental \& Resource Economics, 33, 251-264.

Alkire, S. (2015). Well-being, happiness, and public policy. Thimphu: The Centre for Bhutan Studies \& GNH Research.

Allen, S. G. (1983). How much does absenteeism cost? The Journal of Human Resources, 18(3), 379-393.

Allgöwer, A., Wardle, J., \& Steptoe, A. (2001). Depressive symptoms, social support, and personal health behaviors in young men and women. Health Psychology, 20(3), 223-227.

Anda, R., Williamson, D., Jones, D., MacEra, C., Eaker, E., Glassman, A., et al. (1993). Depressed affect, hopelessness, and the risk of ischemic heart disease in a cohort of U.S. Adults. Epidemiology, 4(4), 285-294.

Aspinwald, L. G. (1998). Rethinking the role of positive affect in self-regulation. Motivation and Emotion, 22(1), 1-32.

Baron, R. A., Fortin, S. P., Frei, R. L., Hauver, L. A., \& Shack, M. L. (1990). Reducing organizational conflict: The role of socially-induced positive affect. The International Journal of Conflict Management, $1,133-152$. 
Barsane, S. G., \& Gibson, D. (2007). Why does affect matter in organizations? Academy of Management Perspectives, 21(1), 36-59.

Beale, S., Bending, M., \& Trueman, P. (2007). An economic analysis of environmental interventions that promote physical activity. York Health Economics Consortium: University of York.

Berry, D. S., \& Hansen, J. S. (1996). Positive affect, negative affect, and social interaction. Journal of Personality and Social Psychology, 71, 796-809.

Bevan, S. (2010). The business case for employees health and wellbeing: A report prepared for Investors in People UK. The Work Foundation. http://investorsinpeople.ph/wp-content/uploads/2013/08/The-Busi ness-Case-for-Employee-Health-and-Wellbeing-Feb-2010.pdf. Last accessed January 2016.

Boehm, J., \& Kubzansky, L. (2012). The heart's content: The association between positive psychological well-being and cardiovascular health. Psychological Bulletin, 138(4), 655-691.

Boehm, J. K., \& Lyubomirsky, S. (2008). Does happiness lead to career success? Journal of Career Assessment, 16, 101-116.

Bowling, N., Eschleman, K., \& Wang, Q. (2010). A meta-analytic examination of the relationship between job satisfaction and subjective well-being. Journal of Occupational and Organizational Psychology, $83,915-934$.

Boyle, P., Buchman, A., \& Bennett, D. (2010). Purpose in life is associated with a reduced risk of incident disability among community-dwelling older persons. American Journal of Geriatric Psychiatry, 18(12), 1093-1102.

Bryson, A., Forth, J., \& Stokes, L. (2015). Does worker wellbeing affect workplace performance? Centre for Economic Performance CEP Discussion Paper No. 1363.

Buettner, T., \& Spengler, H. (2003). Local determinants of crime: Distinguishing between resident and nonresident offenders. ZEW Discussion Paper No 03-13. http://zew.de/pub/zew-docs/dp/dp0313.pdf. Last Accessed December 2015.

Bush, D., Ziegelstein, R., Tayback, M., Richter, D., Stevens, S., Zahalsky, H., et al. (2001). Even minimal symptoms of depression increase mortality risk after acute myocardial infarction. American Journal of Cardiology, 88, 337-341.

Buunk, A., Peiro, J. M., Rocabert, E., \& Dijkstra, P. (2016). Life satisfaction and status among adolescent law offenders. Criminal Behaviour and Mental Health, 26(2), 94-100.

Caldwell, R. M., Silverman, J., Lefforge, N., \& Silver, N. C. (2010). Adjudicated Mexican American adolescents: The effects of familial emotional support on self-esteem, emotional well-being, and delinquency. The American Journal of Family Therapy, 32(1), 55-69.

Cameron, L. D., Brown, P., \& Chapman, J. (1998). Social value orientations and decisions to take proenvironmental action. Journal of Applied Social Psychology, 28(8), 675-697.

Carrico, A., \& Moskowitz, J. (2014). Positive affect promotes engagement in care after HIV diagnosis. Health Psychology, 33(7), 686-689.

Challen, A., Noden, P., West, A., \& Machin, S. (2011). UK resilience programme evaluation: Final report. Department for Education. Research Report DFE-RR097.

Chiang-Ming, C., Chia-Yu, Y., \& Ching-Hsing, C. (2014). Volunteering and life satisfaction: An investigation of endogeneity. Hitotsubashi Journal of Economics, 55, 21-32.

Chida, Y., \& Steptoe, A. (2008). Positive psychological well-being and mortality: A quantitative review of prospective observational studies. Psychosomatic Medicine, 70, 741-756.

CIPD. (2009). Recruitment, retention and turnover. Annual Survey Report 2009. www.cipd.co.uk.

CIPD. (2010). Absence management. Annual Survey Report 2010. www.cipd.co.uk.

Cohen, S., Doyle, W. J., Turner, R. B., Alper, C. M., \& Skoner, D. P. (2003). Emotional style and susceptibility to the common cold. Psychosomatic Medicine, 65, 652-657.

Cohen, S., \& Pressman, S. (2006). Positive affect and health. Current Directions in Psychological Science, $15,122-125$.

Conlon, G., \& Patrignani, P. (2015). The earnings and employment returns to A levels: A report to the Department for Education. London: London Economics.

Cornaglia, F., Feldman, N. E., \& Leigh, A. (2014). Crime and mental well-being. Journal Human Resources, 49, 110-140.

Cox, J., Bowen, M., \& Kempton, O. (2012). Social value: Understanding the wider value of public policy interventions. New Economy Working Papers, Number 008, May 2012.

Credè, M., Chernyshenko, O. S., Stark, S., Dalal, R. S., \& Bashshur, M. (2007). Job satisfaction as mediator: An assessment of job satisfaction's position within the nomological network. Journal of Occupational and Organizational Psychology, 80, 515-538.

Cunado, J., \& de Gracia, F. P. (2013). Environment and happiness: New evidence from Spain. Social Indicators Research, 112, 549-567. 
Cunningham, M. R. (1988). What do you do when you're happy or blue? Mood, expectancies, and behavioral interest. Motivation and Emotion, 12(4), 309-331.

Da Silva, M. A., Singh-Manoux, A., Brunner, E. J., Kaffashian, S., Shipley, M. J., Kivimäki, M., et al. (2012). Bidirectional association between physical activity and symptoms of anxiety and depression: The Whitehall II study. European Journal of Epidemiology, 27, 537-546.

De Neve, J.-E., Diener, E., Tay, L., \& Xuereb, C. (2013). The objective benefits of subjective well-being. In J. Helliwell, R. Layard, \& J. Sachs (Eds.), World happiness report 2013 (pp. 54-79). New York: UN Sustainable Development Solutions Network.

De Neve, J.-E., \& Oswald, A. J. (2012). Estimating the influence of life satisfaction and positive affect on later income using sibling fixed effects. PNAS Proceedings of the National Academy of Sciences, 109(49), 19953-19958.

DECC. (2015). Updated short-term traded carbon values used for UK public policy appraisal. London: Department of Energy and Climate Change. https://www.gov.uk/government/uploads/system/uplo ads/attachment_data/file/477540/Updated_short-term_traded_carbon_values_used_for_UK_policy_ appraisal_2015_.pdf Accessed January 2016.

Delgado, M., Ettekal, A. V., Simpkins, S. D., \& Schaefer, D. R. (2016). How do my friends matter? Examining Latino Adolescents' friendships, school belonging, and academic achievement. Journal of Youth and Adolescence, 45(6), 1120-1125.

Department for Education. (2011). Youth Cohort Study \& Longitudinal Study of young people in England. The activities and experiences of 19 year olds: England 2010. Statistical Bulletin B01/2011.

Diener, E., \& Chan, M. (2011). Happy people live longer: Subjective well-being contributes to health and longevity. Applied Psychology: Health and Wellbeing, 3(1), 1-43.

Diener, E., \& Emmons, R. (1984). The independence of positive and negative affect. Journal of Personality and Social Psychology, 47, 1105-1117.

Diener, E., Emmons, R., Larsen, R., \& Griffin, S. (1985). The satisfaction with life scale. Journal of Personality Assessment, 49(1), 71-75.

Diener, E., Oishi, S., \& Lucas, R. (2003). Personality, culture, and subjective well-being: Emotional and cognitive evaluations of life. Annual Review of Psychology, 54, 403-425.

Diener, E., \& Seligman, M. E. P. (2002). Very happy people. Psychological Science, 13, 81-84.

Diener, E., Smith, H., \& Fujita, F. (1995). The personality structure of affect. Journal of Personality and Social Psychology, 69(1), 130-141.

Diener, E., Suh, E. M., Lucas, R. E., \& Smith, H. L. (1999). Subjective well-being: Three decades of progress. Psychological Bulletin, 125, 276-302.

Dodge, R., Daly, A., Huyton, J., \& Sanders, L. (2012). The challenge of defining wellbeing. International Journal of Wellbeing, 2(3), 222-235.

Dolan, P., \& Metcalfe, R. (2012). Measuring subjective wellbeing: Recommendations on measures for use by national governments. Journal of Social Policy, 41(2), 409-427.

Dolan, P., \& White, M. P. (2007). How can measures of subjective well-being be used to inform public policy? Perspectives on Psychological Science, 2, 71-85.

Duroy, Q. (2008). Testing the affluence hypothesis: A cross-cultural analysis of the determinants of environmental action. The Social Science Journal, 45, 419-439.

Easterlin, R. (2001). Income and happiness: Towards a unified theory. The Economic Journal, 111(473), $465-484$.

Easterlin, R. (2003). Explaining happiness. Proceedings of the National Academy of Sciences, 100(19), $11176-11183$.

Evans, L. (undated). Not present and not correct: Understanding and preventing school exclusions. Report for Barnado's. http://www.barnardos.org.uk/not_present_and_not_correct.pdf. Last accessed January 2016.

Everson, S. A., Roberts, R. E., Goldberg, D. E., \& Kaplan, G. A. (1998). Depressive symptoms and increased risk of stroke mortality over a 29-year period. Archive of Internal Medicine, 158, 1133-1138.

Field, T., Diego, M., \& Hernandez-Reif, M. (2006). Prenatal depression effects on the fetus and newborn: A review. Infant Behavior \& Development, 29, 445-455.

Flook, L., Repetti, R. L., \& Ullman, J. B. (2005). Classroom social experiences as predictors of academic performance. Developmental Psychology, 41(2), 319-327.

Foreman-Peck, J., \& Foreman-Peck, L. (2007). Cognitive achievement and behaviour in school. In Paper presented at the PAS/NPD user Group workshop, University of Bristol. http://www.bristol.ac.uk/medi a-library/sites/cmpo/migrated/documents/peck.pdf.

Forgas, J. P. (1994). The role of emotion in social judgments: An introductory review and an Affect Infusion Model (AIM). European Journal of Social Psychology, 24, 1-24. 
Fredrickson, B. L. (2001). The role of positive emotions in positive psychology: The broaden-and-build theory of positive emotions. American Psychologist, 56(3), 218-226.

Fredrickson, B. L., \& Levenson, R. W. (1998). Positive emotions speed recovery from the cardiovascular sequelae of negative emotions. Cognition and Emotion, 12, 191-220.

Fredrickson, B. L., Mancuso, R. A., Branigan, C., \& Tugade, M. M. (2000). The undoing effect of positive emotions. Motivation and Emotion, 24, 237-258.

Frey, B. S., \& Stutzer, A. (2005). Happiness research: State and prospects. Review of Social Economy, 62, 207-228.

Fujiwara, D. (2013). A general method for valuing non-market goods using wellbeing data: Three-stage wellbeing valuation. Centre for Economic Performance CEP Discussion Paper No. 1233.

Fujiwara, D., Leach, M., Vine, J., \& Trotter, L. (2014). Measuring the social impact of community investment: A guide to using the wellbeing valuation approach. HACT. www.hact.org.uk.

Gibbons, S., \& Silva, O. (2011). School quality, child wellbeing and parents' satisfaction. Economics of Education Review, 30, 312-331.

Gillen-O'Neill, C., \& Fuligni, A. (2013). A longitudinal study of school belonging and academic motivation across high-school. Child Development, 84(2), 678-692.

Gilman, R., \& Huebner, E. S. (2006). Characteristics of adolescents who report very high life satisfaction. Journal of Youth and Adolescence, 35(3), 311-319.

Grant, N., Wardle, J., \& Steptoe, A. (2009). The relationship between life satisfaction and health behavior: A cross-cultural analysis of young adults. International Journal of Behavioral Medicine, 16, 259-268.

Griep, Y., Hyde, M., Vantilborgh, T., Bidee, J., De Witte, H., \& Pepermans, R. (2015). Voluntary work and the relationship with unemployment, health, and well-being: A two-year follow-up study contrasting a materialistic and psychosocial pathway perspective. Journal of Occupational Health Psychology, 20(2), 190-204.

Gutman, L. S., \& Brown, J. (2008). The importance of social worlds: an investigation of peer relationships (p. 29). Report No: Centre for Research on the Wider Benefits of Learning.

Gutman, L. M., \& Feinstein, L. (2008). Children's well-being in primary school: Pupil and school effects (p. 25). Report No: Centre for Research on the Wider Benefits of Learning.

Gutman, L. M., \& Vorhaus, J. (2012). The impact of pupil behaviour and wellbeing on educational outcomes. Department for Education. Research Paper DFE-RR253.

Hagerty, M., \& Veenhoven, R. (2003). Wealth and happiness revisited: Growing national income does go with greater happiness. Social Indicators Research, 64(1), 1-27.

Haldane, A. G. (2014). In giving, how much do we receive? The social value of volunteering. Speech for a Pro Bono Economics lecture to the Society of Business Economists, London 9 September 2014. http ://www.bankofengland.co.uk/publications/Documents/speeches/2014/speech756.pdf.

Haney, P., \& Durlak, J. A. (1998). Changing self-esteem in children and adolescents: A meta-analytical review. Journal of Clinical Child Psychology, 27(4), 423-433.

Hayward, H., Hunt, E., \& Lord, A. (2014). The economic value of key intermediate qualifications: Estimating the returns and lifetime productivity gains to GCSEs, A levels and apprenticeships. Department for Education. Research Report December 2014.

Helliwell, J. F., Layard, R., \& Sachs, J. (2013). World happiness report 2013 (pp. 54-79). New York: UN Sustainable Development Solutions Network.

Hicks, S., Tinkler, L., \& Allin, P. (2013). Measuring subjective well-being and its potential role in policy: Perspectives from the UK Office for national statistics. Social Indicators Research, 114, 73-86.

Hill, P., \& Turiano, N. (2014). Purpose in life as a predictor of mortality across adulthood. Psychological Science, 25(7), 1482-1486.

ONS, R. F. (2013). Household satellite accounts-valuing voluntary activity in the UK. London: Office for National Statistics.

HACT., \& Fujiwara, D. (undated). Community Investment values from the Social Value Bank. www.soci alvaluebank.org.

HM Treasury. (2011). The Green Book: Appraisal and evaluation in central government. Treasury Guidance. London: HM Treasury. https://www.gov.uk/government/uploads/system/uploads/attachment_ data/file/220541/green_book_complete.pdf. Accessed December 2015.

Home Office. (2005). The economic and social costs of crime against individuals and households. Home Office Online Report 30/05. London: Home Office. http://webarchive.nationalarchives.gov.uk/2010 0413151441, www.homeoffice.gov.uk/rds/pdfs05/rdsolr3005.pdf. Accessed October 2016.

Howell, R. T., Kern, M. L., \& Lyubomirsky, S. (2007). Health benefits: Meta-analytically determining the impact of well-being on objective health outcomes. Health Psychology Review, 1, 83-136.

Hunt, E., \& Vernoit, J. (2014). Valuing educational progress in England: The economic benefits of the progress made in GCSE performance. Department for Education. Research Report December 2014. 
Isen, A. M. (2001). An influence of positive affect on decision making in complex situations: Theoretical issues with practical implications. Journal of Consumer Psychology, 11(2), 75-85.

Isen, A. M., Daubman, K. A., \& Nowicki, G. P. (1987). Positive affect facilitates creative problem solving. Journal of Personality and Positive Psychology, 52, 1122-1131.

Iverson, R., \& Deery, S. (2001). Understanding the "personological" basis of employee withdrawal: The influence of affective disposition on employee tardiness, early departure, and absenteeism. Journal of Applied Psychology, 86, 856-866.

Kahneman, D., \& Krueger, A. B. (2006). Developments in the measurement of subjective well-being. Journal of Economic Perspectives, 20, 3-24.

Kanske, P., \& Kotz, S. A. (2011). Conflict processing is modulated by positive emotion: ERP data from a flanker task. Behavioural Brain Research, 219, 382-386.

Kiecolt-Glaser, J. K., McGuire, L., Robles, T. F., \& Glaser, R. (2002). Emotions, morbidity, and mortality: New perspectives from psychoneuroimmunology. Annual Review of Psychology, 53, 83-107.

Klonoff-Cohen, H., Chu, E., Natarajan, L., \& William, S. (2001). A prospective study of stress among women undergoing in vitro fertilization or gamete intrafallopian transfer. Fertility and Sterility, 76(4), 675-687.

Koizumi, M., Ito, H., Kaneko, Y., \& Motohashi, Y. (2008). Effect of having a sense of purpose in life on the risk of death from cardiovascular diseases. Journal of Epidemiology, 18(5), 191-196.

Krekel, C., \& Poprawe, M. (2014). The effect of local crime on well-being: Evidence for Germany. KOF Working Papers No. 358.

Lawrence, E., Rogers, R., \& Wadsworth, T. (2015). Happiness and longevity in the United States. Social Science and Medicine, 145, 115-119.

Layard, R. (2005). Happiness: Lessons from a new science. London: Penguin Books.

Leung, J., \& Leung, K. (1992). Life satisfaction, self-concept, and relationship with parents in adolescence. Journal of Youth and Adolescence, 21(6), 653-665.

Liu, W., \& Aaker, J. (2008). The happiness of giving: The time-ask effect. Journal of Consumer Research, 35, 543-557.

Lucas, R. E., Clark, A. E., Georgellis, Y., \& Diener, E. (2003). Reexamining adaptation and the set point model of happiness: Reactions to changes in marital status. Journal of Personality and Social Psychology, 84(3), 527-539.

Lucas, R. E., Le, K., \& Dyrenforth, P. S. (2008). Explaining the extraversion/positive affect relation: Sociability cannot account for extraverts' greater happiness. Journal of Personality, 76(3), 385-414.

Lyubomirsky, S., King, L., \& Diener, E. (2005). The benefits of frequent positive affect: Does happiness lead to success? Psychological Bulletin, 131, 803-855.

Mason, H., Jones-Lee, M., \& Donaldson, C. (2009). Modelling the monetary value of a QALY: A new approach based on UK data. Health Economics, 18, 933-950.

Mehl, M. R., Vazire, S., Holleran, S. E., \& Clark, C. S. (2010). Eavesdropping on happiness: Well-being is related to having less small talk and more substantive conversations. Psychological Science, 21(4), 539-541.

Mori, K., Kaiho, Y., Tomata, Y., Narita, M., Tanji, F., Sugiyama, K., et al. (2017). Sense of life worth living (ikigai) and incident functional disability in elderly Japanese: The Tsurugaya Project. Journal of Psychosomatic Research, 95, 62-67.

Morris, M. W., \& Keltner, D. (2000). How emotions work: The social functions of emotional expression in negotiations. Research in Organizational Behaviour, 22, 1-50.

Moskowitz, J. T. (2003). Positive affect predicts lower risk of AIDS mortality. Psychosomatic Medicine, 65, $620-626$.

Moskowitz, J. T., Epel, E. S., \& Acree, M. (2008). Positive affect uniquely predicts lower risk of mortality in people with diabetes. Health Psychology, 27(1 Suppl.), S73-S82.

Mukuria, C., Rowen, D., Peasgood, T., \& Brazier, J. (2015). An empirical comparison of well-being measures used in the UK. Policy Research Unit in Economic Evaluation of Health and Care Interventions. Universities of Sheffield \& York. EEPRU Research Report 027.

O’Donnell, G., Deaton, A., Durand, M., Halpern, D., \& Layard, R. (2014). Wellbeing and policy. Report commissioned by the Legatum Institute.

OECD. (2004). The valuation of environmental health risks to children: synthesis report. Working Party on National Environmental Policy. Environment Directorate, Report ENV/EPOC/WPNEP (2004)15. Paris: OECD.

Oishi, S., Diener, E., \& Lucas, R. (2007). The optimum level of well-being: Can people be too happy? Perspectives on Psychological Science, 2, 346-360.

Ong, A. (2010). Pathways linking positive emotion and health in later life. Current Directions in Psychological Science, 19(6), 358-362. 
Orr, S. T., James, S. A., \& Blackmore Prince, C. (2002). Maternal prenatal depressive symptoms and spontaneous preterm births among African-American women in Baltimore, Maryland. American Journal of Epidemiology, 156, 797-802.

Ostir, G. V., Markides, K. S., Black, S. A., \& Goodwin, J. S. (2000). Emotional wellbeing predicts subsequent functional independence and survival. Journal of the American Geriatrics Society, 48, 473-478.

Ostir, G. V., Markides, K. S., Peek, M. K., \& Goodwin, J. S. (2001). The association between emotional well-being and the incidence of stroke in older adults. Psychosomatic Medicine, 63, 210-215.

Oswald, A., Proto, E., \& Sgroi, D. (2015). Happiness and productivity. Journal of Labor Economics, 33(4), 789-822.

Papathanasopoulou, E., White, M., Hattam, C., Lannin, A., Harvey, A., \& Spencer, A. (2016). Valuing the health benefits of physical activities in the marine environment and their importance for marine spatial planning. Marine Policy, 63, 144-152.

Patel, V., Flisher, A. J., Hetrick, S., \& McGorry, P. (2007). Mental health of young people: A global publichealth challenge. Lancet, 369, 1302-1313.

Paterson, T. S. E., Yeung, S. E., \& Loken Thornton, W. (2016). Positive affect predicts everyday problemsolving ability in older adults. Aging \& Mental Health, 20(8), 1-9.

Pelled, L. H., \& Xin, K. R. (1999). Down and out: An investigation of the relationship between mood and employee withdrawal behavior. Journal of Management, 25, 875-895.

Personal Social Services Research Unit. (2015). Unit costs of health and social care 2015 (compiled by L. Curtis \& A. Burns). PSSRU. http://www.pssru.ac.uk/project-pages/unit-costs/2015/. Last accessed October 2016.

Peterson, S. J., Luthans, F., Avolio, B. J., Walumbwa, F. O., \& Zhang, Z. (2011). Psychological capital and employee performance: A latent growth modelling approach. Personnel Psychology, 64, 427-450.

Pittman, L., \& Richmond, A. (2007). Academic and psychological functioning in late adolescence: The importance of school belonging. The Journal of Experimental Education, 75(4), 270-290.

Powdthavee, N. (2008). Putting a price tag on friends, relatives, and neighbours: Using surveys of life satisfaction to value social relationships. The Journal of Socio-Economics, 37, 1459-1480.

Pressman, S. D., \& Cohen, S. (2005). Does positive affect influence health? Psychological Bulletin, 131, 925-971.

Priller, E., \& Schupp, J. (2011). Social and economic characteristics of financial and blood donors in Germany. DIW Economic Bulletin, 6, 23-30.

Public Health England. (2014). The link between pupil health and wellbeing and attainment: A briefing for head teachers, governers and staff in education settings. London: Public Health England. https:// www.gov.uk/government/uploads/system/uploads/attachment_data/file/370686/HT_briefing_layo utvFINALvii.pdf. Last accessed January 2016.

Quick, A., \& Abdallah, S. (2015). Why personal wellbeing is good for the nation's health. Novacroft. http ://www.novacroft.com/wp-content/uploads/2015/06/Novacroft_Thought_Paper_WELL_BEING.pdf. Last accessed February 2016.

Rasmussen, H., Scheier, M., \& Greenhouse, J. (2009). Optimism and physical health: A meta-analytic review. Annals of Behavioral Medicine, 37, 239-256.

Rego, A., Sousa, F., Marques, C., \& e Cunha, M. P. (2014). Hope and positive affect mediating the authentic leadership and creativity relationship. Journal of Business Research, 67, 200-210.

Rehdanz, L., \& Maddison, D. (2008). Local environmental quality and life-satisfaction in Germany. Ecological Economics, 64, 787-797.

Reiner, M., Niermann, C., Jekauc, D., \& Woll, A. (2013). Long-term health benefits of physical activity: A systematic review of longitudinal studies. BMC Public Health, 13(813), 1-9.

Sabatini, F. (2014). The relationship between happiness and health: Evidence from Italy. Social Science and Medicine, 114, 178-187.

Sainsbury Centre for Mental Health. (2003). The economic and social costs of mental illness. Policy Paper 3. London: Sainsbury Centre for Mental Health.

Schnohr, P., Kristensen, T., Prescott, E., \& Scharling, H. (2005). Stress and life dissatisfaction are inversely associated with jogging and other types of physical activity in leisure time: The Copenhagen City Heart Study. Scandinavian Journal of Medicine and Science in Sports, 15, 107-112.

Staw, B. M., Sutton, R. I., \& Pelled, L. H. (1994). Employee positive emotion and favorable outcomes at the workplace. Organization Science, 5(1), 51-71.

Steptoe, A., Deaton, A., \& Stone, A. (2015). Subjective wellbeing, health, and ageing. Lancet, 385, $640-648$.

Steptoe, A., O’Donnell, K., Marmot, M., \& Wardle, J. (2008). Positive affect, psychological well-being, and good sleep. Journal of Psychosomatic Research, 64, 409-415. 
Steptoe, A., \& Wardle, J. (2011). Positive affect measured using ecological momentary assessment and survival in older men and women. Proceedings of the National Academy of Sciences USA, 108, $18244-18248$.

Steptoe, A., Wardle, J., \& Marmot, M. (2005). Positive affect and health-related neuroendocrine, cardiovascular, and inflammatory processes. Proceedings of the National Academy of Sciences USA, 102, 6508-6512.

Stiglitz, J., Sen, A., \& Fitoussi, J. P. (2009). Report of the commission on the measurement of economic performance and social progress. Paris: Commission on the Measurement of Economic Performance and Social Progress. http://www.stiglitz-sen-fitoussi.fr/en/index.htm. Last accessed August 2016.

Sulemana, I. (2016). Are happier people more willing to make income sacrifices to protect the environment? Social Indicators Research, 127, 447-467.

Tanno, K., Sakata, K., Ohsawa, M., Onodaa, T., Itai, K., Yaegashi, Y., et al. (2009). Associations of ikigai as a positive psychological factor with all-cause mortality and cause-specific mortality among middleaged and elderly Japanese people: Findings from the Japan Collaborative Cohort Study. Journal of Psychosomatic Research, 67, 67-75.

Thoits, P. A., \& Hewitt, L. N. (2001). Volunteer work and well-being. Journal of Health and Social Behavior, 42(2), 115-131.

Ura, K., Alkire, S., Zangmo, T., \& Wangdi, K. (2012). An extensive analysis of GNH index. Thimphu: The Centre for Bhutan Studies. http:/www.grossnationalhappiness.com/wp-content/uploads/2012/10/ An\%20Extensive\%20Analysis\%20of\%20GNH\%20Index.pdf. Last accessed October 2017.

Veenhoven, R. (2008). Healthy happiness: Effect of happiness on physical health and the consequences for preventive health care. Journal of Happiness Studies, 9, 449-469.

Veenhoven, R., \& Hagerty, M. (2006). Rising happiness in nations 1946-2004: A reply to Easterlin. Social Indicators Research, 79(3), 421-436.

Vignoles, A., \& Meschi, E. (2010). The determinants of non-cognitive and cognitive schooling outcomes. In Report to the Department of Children, Schools and Families. Report No. 004.

Waters, L., \& Roach, D. (1971). Relationship between job attitudes and two forms of withdrawal from the work situation. Journal of Applied Psychology, 55(1), 92-94.

Waugh, C., \& Fredrickson, B. L. (2006). Nice to know you: Positive emotions, self-other overlap, and complex understanding in the formation of a new relationship. Journal of Positive Psychology, 1(2), 93-106.

White, M., Elliott, L., Taylor, T., Wheeler, B., Spencer, A., Bone, A., et al. (2016). Recreational physical activity in natural environments and implications for health: A population based cross-sectional study in England. Preventive Medicine. https://doi.org/10.1016/j.ypmed.2016.08.023.

WHO-Europe. (2014). Health economic assessment tools (HEAT) for walking and for cycling. Methodology and user guide. Economic assessment of transport infrastructure and policies. 2014 Update. http:// www.euro.who.int/__data/assets/pdf_file/0010/256168/ECONOMIC-ASSESSMENT-OF-TRAN SPORT-INFRASTRUCTURE-AND-POLICIES.pdf. Last accessed April 2016.

Wiest, M., Schuz, B., Webster, N., \& Wurm, S. (2011). Subjective well-being and mortality revisited: Differential effects of cognitive and emotional facets of well-being on mortality. Health Psychology, 30(6), 728-735.

Xu, J., \& Roberts, R. E. (2010). The power of positive emotions: It's a matter of life or death-Subjective well-being and longevity over 28 years in a general population. Health Psychology, 29, 9-19.

Yuan, L. (2015). The happier one is, the more creative one becomes: An investigation on inspirational positive emotions from both subjective well-being and satisfaction at work. Psychology, 6, 201-209. 